\title{
Efeitos Ambientais que Afetam o Ganho de Peso Pré-Desmama em Animais Angus, Hereford, Nelore e Mestiços Angus-Nelore e Hereford-Nelore ${ }^{1}$
}

\author{
Rodrigo de Almeida Teixeira ${ }^{2}$, Lucia Galvão de Albuquerque ${ }^{3}$
}

\begin{abstract}
RESUMO - Foram utilizados dados de 66.035 animais das raças Nelore, Hereford, Angus e mestiços Nelore x Angus e Nelore x Hereford, para avaliar a influência da idade da vaca, idade do bezerro e data juliana de nascimento sobre o ganho médio diário dos bezerros no período pré-desmama (GMD). A análise estatística revelou que estas três covariáveis tiveram efeito significativo sobre o GMD. Observou-se também que o ajuste linear para idade à desmama não foi suficiente para retirar o seu efeito sobre o GMD. Estes resultados mostram que tais fatores ambientais podem ser importantes fontes de variação para esta característica nos programas de melhoramento genético.
\end{abstract}

Palavras-chave: bovinos de corte, cruzamento, data juliana de nascimento, idade à desmama

\section{Enviromental Effects on Preweaning Daily Gain in Angus, Hereford, Nellore and Angus $X$ Nellore and Hereford $X$ Nellore Crosses}

\begin{abstract}
Nellore, Hereford, Angus and Nellore x Angus and Nellore x Hereford crossbred calves were analyzed to estimate the influence of cow age, age at weaning and the julian birth date on average daily gain from birth to weaning. The statistical analysis indicated that these three covariates had significant effects on this trait. Furthermore, the linear adjustment for age at weaning was not enough to remove this effect on the average daily gain. These results show that these environmental effects can be an important variation source for this trait in animal improvement programs.
\end{abstract}

Key Words: age at weaning, beef cattle, crossbreeding, julian birth date

\section{Introdução}

O uso dos cruzamentos entre raças em gado de corte resulta em vantagens na maioria das características de produção. Há condição de se produzirem animais eficientes nos mais diversos ambientes, por intermédio da combinação de cruzamentos e seleção, processos independentes, mas que devem ser sinérgicos.

Alguns autores (Campos et al., 1989; Fries, 1996a,b; Bocchi et al., 1999) destacam a importância de efeitos ambientais como a idade da vaca, a idade do bezerro à desmama $\mathrm{e}$ a data juliana de nascimento sobre $\mathrm{o}$ ganho de peso do nascimento à desmama. Para que animais criados em diferentes condições de ambiente possam ser distinguidos e comparados, é necessário que os efeitos de fatores ambientais sobre as características de interesse estejam bem definidos.

No presente trabalho foram utilizados dados de rebanhos comerciais das raças Angus, Hereford, Nelore e cruzados Angus x Nelore e Hereford x Nelore para estimar os efeitos de idade da vaca, idade à desmama e data juliana de nascimento sobre o ganho médio diário de peso dos bezerros do nascimento à desmama.

\section{Material e Métodos}

Foram utilizados dados coletados à desmama de 66.035 animais das raças Nelore, Angus, Hereford e produtos de cruzamentos de Angus e Hereford com Nelore, de rebanhos comerciais que fazem partem dos grupos Natura e Conexão Braford. Após verificação da distribuição dos dados e cálculo de médias, as análises estatísticas foram realizadas utilizando-se o procedimento GLM (SAS, 1998). Inicialmente, o modelo proposto utilizou o ganho médio diário do nascimento à desmama (GMD) como variável dependente e incluiu grupo contemporâneo (GC) como efeito fixo, além de analisar, separadamente, como classe, cada um dos efeitos de meio, idade da vaca ao parto, idade do bezerro à desmama e data juliana de nascimento. A seguir, tais efeitos foram modelados por meio de polinômios ordinários e segmentados. A determinação dos segmentos foi realizada, inicialmente, por inspeção, por intermédio de um diagrama de pontos, a fim de detectar os pontos de mudança de comportamento da curva. Os coeficientes de regressão para os efeitos de meio foram

\footnotetext{
${ }^{1}$ Parte da dissertação de mestrado em Genética e Melhoramento Animal da FCAV - UNESP, financiada pela FAPESP.

2 Zootecnista-Doutorando pelo DZ da FCAV - UNESP/Jaboticabal, SP. E.mail: rodrigot@fcav.unesp.br

3 Professora Assistente Doutora - DZ - FCAV - UNESP/Jaboticabal, SP. Pesquisadora do CNPq. E.mail: Igalb@fcav.unesp.br
} 
obtidos por intermédio da análise conjunta com os efeitos fixos de composição genética do bezerro e da vaca, além da heterozigose individual e materna.

Os efeitos fixos considerados foram:

- Grupo contemporâneo, definido como: fazenda, retiro e grupo de manejo ao nascimento e à desmama, ano de nascimento e sexo do bezerro;

Como covariáveis, utilizaram-se:

- Idade da vaca ao parto, Idade do bezerro à desmama e Data juliana de nascimento;

- Heterozigose individual e materna (efeito linear);

- Fração de genes Angus do bezerro e da vaca;

- Fração de genes Hereford do bezerro e da vaca.

O efeito da idade da vaca (IDVC) foi modelado separadamente para machos e fêmeas (Bocchi et al., 1999) com um polinômio segmentado quadráticoquadrático, função composta por dois segmentos quadráticos e quatro parâmetros livres. O "nó" ou ponto de junção foi estimado aos sete anos de idade da vaca utilizando como critério a maximização do coeficiente de determinação. O mesmo procedimento foi utilizado para modelar o efeito da data juliana de nascimento (DNJU), porém neste caso, utilizou-se um polinômio segmentado quadrático-quadráticoquadrático com "nós" estimados em 175 e 270 dias.

A idade do bezerro à desmama (IDDES) foi descrita no modelo por uma regressão linear simples (polinômio ordinário).

\section{Resultados e Discussão}

As estatísticas descritivas (média, desvio-padrão e amplitude) das variáveis estudadas são apresentadas na Tabela 1.

A IDVC apresentou efeito significativo $(\mathrm{P}<0,0001)$ sobre o GMD para os dois segmentos quadráticos, tanto para machos como para fêmeas. Este comportamento biologicamente esperado foi semelhante aos encontrados por Campos et al. (1989), Fries (1996a), Paz (1997) e Bocchi et al. (1999).

Foi observado também maior ganho médio diário para os bezerros cujas mães estavam próximas de sete anos de idade. Além dos machos apresentarem maior GMD, eles foram mais influenciados pela idade da vaca, uma vez que as fêmeas apresentaram uma curva mais achatada (Figura 1).

Os fatores de correção para ajustar o ganho médio diário pré-desmama em função do efeito da idade da vaca ao parto tanto para machos como para fêmeas foram estimados tomando como base a idade de 7 anos e são apresentados resumidamente na Tabela 2. Os valores obtidos variaram de 1 a 1,1916 para machos e de 1 a 1,2016 para fêmeas.

Em relação à IDDES, vale lembrar que a Beef Improvement Federation (BIF, 1996) recomenda apenas ajuste linear para animais entre 160 e 250 dias de idade, porém, esta mesma instituição ressalva que apenas ajuste linear para idade pode não ser suficiente para retirar todo o efeito da idade. Neste estudo tal ajuste linear foi feito uma vez que se trabalhou com o GMD. Mesmo assim a idade à desmama ainda apresentou efeito linear significativo $(\mathrm{P}<0,0001)$ sobre o ganho de peso pré-desmama. Este resultado confirma que apenas um ajuste linear para idade não foi suficiente para retirar todo o efeito da idade sobre o crescimento até a desmama (Figura 2).

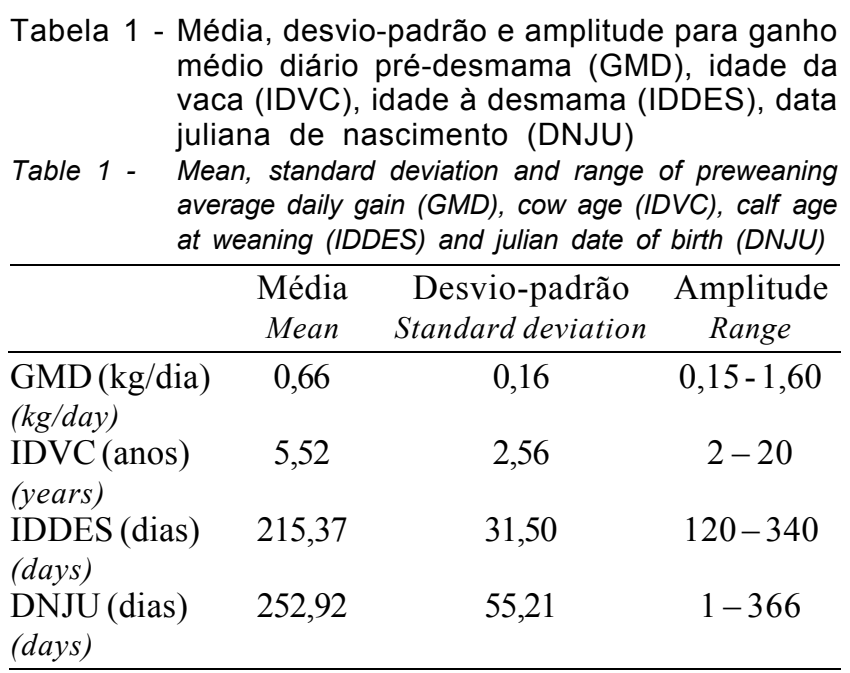

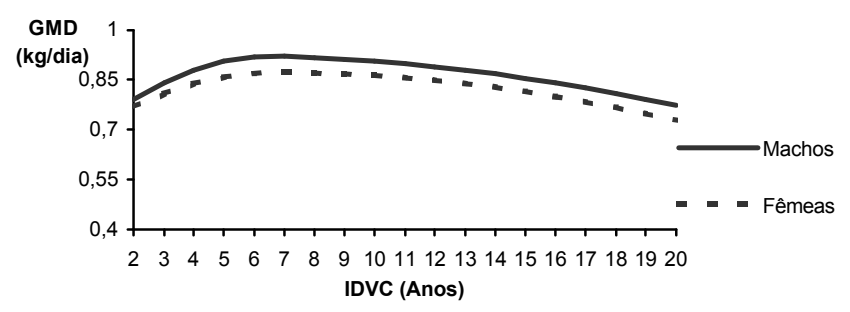

Figura 1 - Idade da vaca (IDVC) sobre o ganho médio diário pré-desmama (GMD) para machos e fêmeas.

Figure 1 - Age of cow (IDVC) effect on preweaning daily gain (GMD) for males and females. 
Os fatores de correção estimados para ajustar o ganho médio diário pré-desmama em função da idade do bezerro à desmama foram estimados tomando como base a idade de 230 dias e são apresentados resumidamente na Tabela 3. Tais fatores variaram entre 0,8342 e 1,2480, mostrando diferenças de até $33 \%$ entre os animais mais jovens e os mais velhos à desmama.

Para a DNJU foi encontrado efeito significativo de todos os segmentos do polinômio. Apesar de terem sido utilizados dados de nascimentos durante todo o ano, verificou-se maior concentração natural dos dados no segundo semestre. Os animais que nasceram mais cedo dentro da estação de nascimento da primavera apresentaram melhor GMD (Figura 3). Isto ocorre pela maior produção de leite de suas mães que atingem o pico de produção na época de maior disponibilidade de forragem. Dividindo-se o ano em quatro estações com períodos de 90 dias, verificou-se que a média em GMD na estação 3 (entre os dias 180 e 270) foi de $0,70 \mathrm{~kg} / \mathrm{dia}$, enquanto este mesmo valor para a estação 1 (entre os dias 1 e 90) foi de apenas $0,61 \mathrm{~kg} / \mathrm{dia}$ (Tabela 4).

Campos et al. (1989) e Fries (1996b) verificaram o mesmo tipo de comportamento da variável GMD em relação à data de nascimento. Isto mostra que para estas condições é importante utilizar uma estação de monta que concentre os nascimentos no início do segundo semestre.

Os fatores de correção estimados para ajustar o ganho médio diário pré-desmama, em função da data juliana de nascimento, tanto para machos como para fêmeas, foram estimados tomando como base os dias $45,135,225$ e 315 do calendário juliano, que correspondem ao meio de cada estação do ano. Tais fatores variaram entre 0,90869 e 1,04108 e são apresentados resumidamente na Tabela 5 .

Foi possível verificar a necessidade de utilizar fatores de ajuste que permitam comparações entre animais provenientes de diferentes condições de ambiente uma vez que tais fatores afetam o desempenho em ganho de peso no período pré-desmama.

Tabela 2 - Fatores de correção para ganho médio diário pré-desmama (GMD), em função da idade da vaca (IDVC) Table 2 - Cow age adjustment factors for preweaning average daily gain (GMD)

\begin{tabular}{lcccc}
\hline IDVC (anos) & $\begin{array}{c}\text { GMD predito machos } \\
\text { Predicted GMD }\end{array}$ & $\begin{array}{c}\text { Fator de correção } \\
\text { Correction factor }\end{array}$ & $\begin{array}{c}\text { GMD predito fêmeas } \\
\text { Predicted GMD }\end{array}$ & $\begin{array}{c}\text { Fator de correção } \\
\text { Correction factor }\end{array}$ \\
\hline 02 & 0,7926 & 1,1619 & 0,7665 & 1,1397 \\
07 & 0,9210 & 1,0000 & 0,8736 & 1,0000 \\
20 & 0,7729 & 1,1916 & 0,7270 & 1,2016 \\
\hline
\end{tabular}

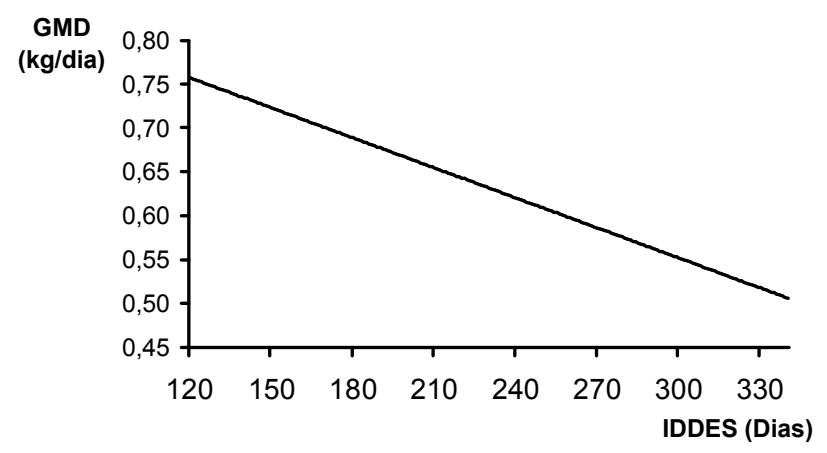

Figura 2 - Ganho médio diário pré-desmama predito (GMD), de acordo com a idade à desmama do bezerro (IDDES).

Figure 2 - Preweaning average daily gain (GMD), according to calf age at weaning (IDDES).

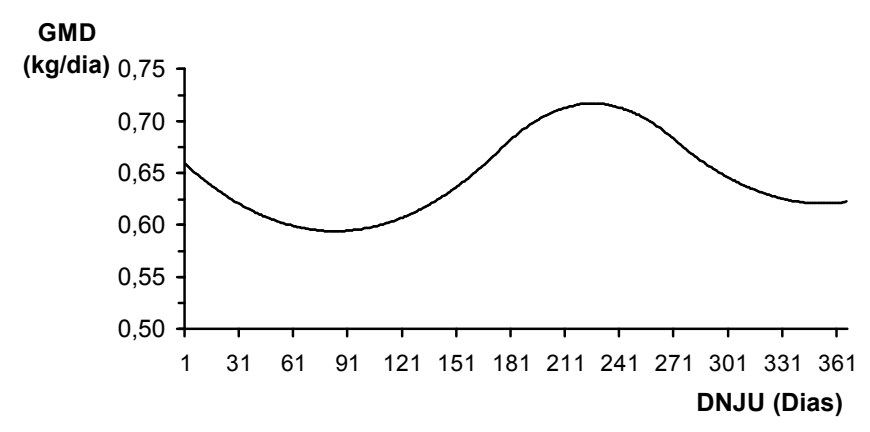

Figura 3 - Ganho médio diário pré-desmama predito (GMD), de acordo com a data juliana de nascimento (DNJU).

Figure 3 - Preweaning average daily gain (GMD), according to calf julian date of birth (DNJU).

R. Bras. Zootec., v.32, n.4, p.887-890, 2003 
Tabela 3 - Fatores de correção para ganho médio diário pré-desmama (GMD), em função da idade à desmama (IDDES)

Table 3 - Preweaning average daily gain (GMD) adjustment factors, according to calf age at weaning (IDDES)

\begin{tabular}{lcc}
\hline IDDES (dias) & $\begin{array}{c}\text { GMD predito } \\
\text { predicted GMD }\end{array}$ & $\begin{array}{c}\text { Fator de correção } \\
\text { Correction factor }\end{array}$ \\
\hline IDDES (days) & 0,7572 & 0,8342 \\
230 & 0,6317 & 1,0000 \\
340 & 0,5062 & 1,2480 \\
\hline
\end{tabular}

\section{Conclusões}

O desempenho em ganho de peso diário no período pré-desmama foi influenciado pelos efeitos de idade à desmama, data juliana de nascimento dos bezerros e idade da vaca ao parto.

A utilização de ajuste linear para o efeito de idade do bezerro à desmama não foi suficiente para remover todo o efeito da idade sobre o GMD do nascimento à desmama.

Tabela 4 - Médias de ganho médio diário observado (GMD - kg/dia) por estação de nascimento Table 4 - Means of average daily gain (GMD - kg/day), according to birth season

\begin{tabular}{lccc}
\hline & $\begin{array}{c}\text { GMD médio } \\
\text { GMD means }\end{array}$ & $\begin{array}{c}\text { Mínimo } \\
\text { Minimum }\end{array}$ & $\begin{array}{c}\text { Máximo } \\
\text { Maximum }\end{array}$ \\
\hline $\begin{array}{l}\text { Estação 1 (janeiro a março) } \\
\text { Season 1 (January to March) }\end{array}$ & 0,6141 & 0,5939 & 0,6586 \\
$\begin{array}{l}\text { Estação 2 (abril a junho) } \\
\text { Season 2 (April to June) }\end{array}$ & 0,6251 & 0,5945 & 0,6795 \\
$\begin{array}{l}\text { Estação 3 (julho a setembro) } \\
\text { Season 3 (July to September) }\end{array}$ & 0,7051 & 0,6811 & 0,7166 \\
$\begin{array}{l}\text { Estação 4 (outubro a dezembro) } \\
\text { Season 4 (October to December) }\end{array}$ & 0,6388 & 0,6207 & 0,6831 \\
\hline
\end{tabular}

Tabela 5 - Fatores de correção para ganho médio diário pré-desmama (GMD) em função da data juliana de nascimento (DNJU)

Table 5 - Preweaning average daily gain (GMD) adjustment factors, according to julian date of birth (DNJU)

\begin{tabular}{ccc}
\hline DNJU (dias) & $\begin{array}{c}\text { GMD predito } \\
\text { Predicted GMD }\end{array}$ & $\begin{array}{c}\text { Fator de correção } \\
\text { Correction factor }\end{array}$ \\
\hline 1 & 0,6586 & 0,9233 \\
91 & 0,5946 & 1,0411 \\
181 & 0,6826 & 1,0498 \\
271 & 0,6817 & 0,9296 \\
366 & 0,6224 & 1,0181 \\
\hline
\end{tabular}

\section{Agradecimento}

À empresa GenSys Consultores Associados S/C Ltda., pelo fornecimento dos dados, e à FAPESP, pelo apoio para execução deste estudo.

\section{Literatura Citada}

BEEF IMPROVEMENT FEDERATION. Guidelines for uniform beef improvement programs. Raleigh: U.S. Department of Agriculture, North Carolina State University, 1996. 155 p.

BOCCHI, A.L.; FRIES, L.A.; ALBUQUERQUE, L.G. Efeito da idade da vaca e da data juliana de nascimento sobre o ganho médio diário de bezerros de corte durante o período prédesmame. In: REUNIÃO ANUAL DA SOCIEDADE BRASILEIRA DE ZOOTECNIA, 36., 1999, Porto Alegre. Anais... Viçosa: Sociedade Brasileira de Zootecnia, 1999. p.154.

CAMPOS, L.T.; SILVA, P.R.; FRIES, L.A. Fatores de correção para efeitos ambientais que afetam o ganho de peso do nascimento à desmama em bovinos da raça Nelore. Coletânea de pesquisas inéditas sobre zebu. Uberaba: Empresa de Pesquisa Agropecuária de Minas Gerais, 1989. p.108-123.

FRIES, L.A. Efeito da idade da vaca sobre o peso à desmama em zebuínos. In: SIMPÓSIO NACIONAL DE MELHORAMENTO ANIMAL, 1., 1996, Ribeirão Preto. Anais ... Ribeirão Preto: Sociedade Brasileira de Melhoramento Animal, 1996a. p.255-256.

FRIES, L.A. Efeito da data de nascimento sobre o peso à desmama em zebuínos. In: SIMPÓSIO NACIONAL DE MELHORAMENTO ANIMAL, 1., 1996, Ribeirão Preto. Anais ... Ribeirão Preto: Sociedade Brasileira de Melhoramento Animal, 1996b. p.249-250.

PAZ, C.C.P. Efeitos ambientais e genéticos que afetam o ganho de peso pré-desmame em bovinos da raça Nelore. Jaboticabal: Universidade Estadual Paulista, 1997. 117p. Dissertação (Mestrado em Zootecnia) - Universidade Estadual Paulista, 1997.

SAS INSTITUTE . SAS Language Guide, v. 6.03. Cary: 1995. $530 \mathrm{p}$.

Recebido em: 14/05/02 Aceito em: 11/12/02

R. Bras. Zootec., v.32, n.4, p.887-890, 2003 